This item was submitted to Loughborough's Research Repository by the author.

Items in Figshare are protected by copyright, with all rights reserved, unless otherwise indicated.

\title{
Evaluating alternative concepts of bus-based park and ride
}

PLEASE CITE THE PUBLISHED VERSION

http://dx.doi.org/10.1016/j.tranpol.2010.09.006

PUBLISHER

(c) Elsevier

VERSION

AM (Accepted Manuscript)

LICENCE

CC BY-NC-ND 4.0

REPOSITORY RECORD

Meek, Stuart, Stephen G. Ison, and Marcus P. Enoch. 2019. "Evaluating Alternative Concepts of Bus-based Park and Ride". figshare. https://hdl.handle.net/2134/12698. 
This item was submitted to Loughborough's Institutional Repository (https://dspace.lboro.ac.uk/) by the author and is made available under the following Creative Commons Licence conditions.

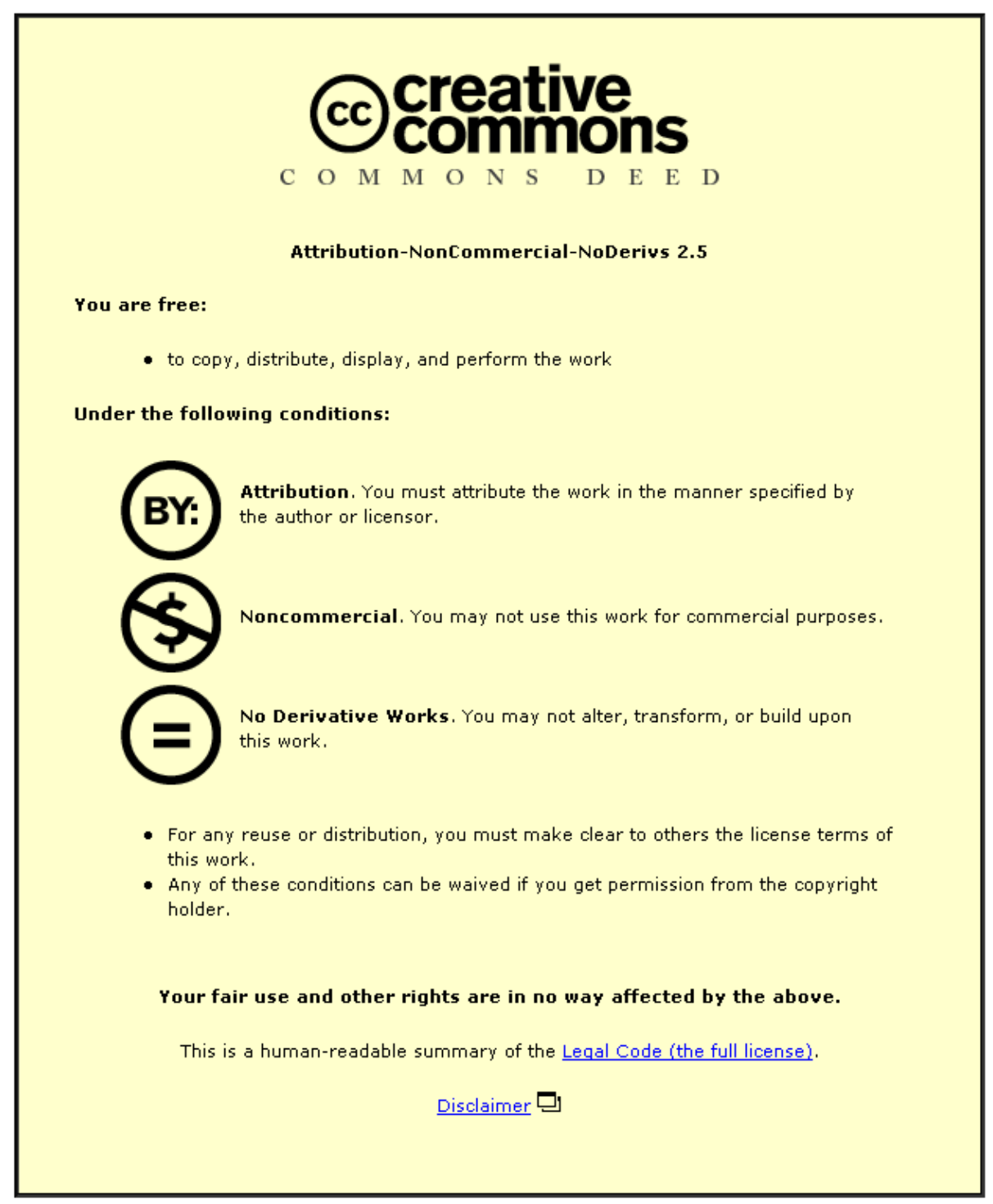

For the full text of this licence, please go to: http://creativecommons.org/licenses/by-nc-nd/2.5/ 


\title{
Evaluating Alternative Concepts of Bus-based Park and Ride
}

Stuart Meek, Stephen Ison, and Marcus Enoch,

Transport Studies Group, School of Civil and Building Engineering, Loughborough University, Loughborough, Leicestershire, LE11 3TU, United Kingdom.

Keywords: Park-and-Ride, Interchange, Bus, Integration

\begin{abstract}
Whilst it has been used since the 1960s, the UK government have promoted bus-based Park and Ride (P\&R) particularly heavily over the last 20 years as a tool to deal with traffic congestion and air pollution. Evidence on its effects indicates that it may be counter-productive in these terms though. This paper aims to consider alternative forms of car-bus interchange in the context of traffic reduction. The evidence on both current and future concepts is derived from a large survey of P\&R users in Cambridge, UK. It is suggested that while current P\&R significantly increases the vehicle miles travelled by its users, some of the alternative models presented may offer considerable improvements.
\end{abstract}

\section{Introduction}

For over 40 years, an inherently fixed model of bus-based P\&R has been used in the UK. It consists of a dedicated car park with several hundred spaces which is located on the edge of its host city, easily accessible from radial routes and served by frequent bus services to the urban core. Yet the policy goals to which it has been subjected have been fluid. Originally, it was used by local authorities to add capacity to their urban parking stock. Subsequently though, awareness of the environmental impacts of transport has increased and the UK government has moved away from building roads to meet higher levels of transport demand and towards encouraging alternative modes. As such, P\&R was encouraged through government policy as a traffic reduction and environmental policy (e.g. DoE, 1990; DETR, 1998; 2000) which resulted in increased take-up by local authorities, with over 50 UK P\&R sites constructed during the 1990s.

As is detailed in the following section of this paper though, considerable doubt was raised by some in the mid-1990s over the traffic reduction capabilities of P\&R (notably Parkhurst, 1995). Indeed, it undoubtedly increases urban parking stocks (and is therefore economically favourable) but its role in traffic reduction is rather more complex than simply inducing a switch to the bus for the final part of users' trips. Because its use is not exclusive to motorists - it also tends to attract those who would not otherwise travel and users of conventional bus services (because of the price, quality and time benefits) - some degree of modal shift to the car for access to the P\&R service is encouraged.

Thus, the government set about clarifying the role of P\&R in transport policy (WSA, 1998), but the report that they commissioned was shown by Parkhurst (1999) to exclude important elements in the full traffic effects of P\&R. This included the vehicle miles travelled (VMT) of the high-frequency P\&R buses and the VMT of those who would alternatively use conventional public transport, travel elsewhere or make no trip. 
Unfortunately however, there has hitherto been a dearth of research to include these factors. Since the early-2000s however, explicit government support for P\&R has waned (see Meek et al, 2008 for a full discussion of P\&R policy). Yet national government funding remains for schemes through the Local Transport Plan (LTP) process and they remained popular in the second round of LTPs which cover the period 2006-2011.

Hence, while there is little doubt on the popularity side of P\&R as a transport policy, the evidence (even though sparse and dated) on its traffic reduction effects is less favourable. This paper considers whether the current way in which $P \& R$ is designed - with a large site located on the fringe of its host city, supported by high-frequency buses - may be modified in order to induce more favourable results in terms of its traffic effects. Of course, given the dearth of contemporary data, the paper also reopens the debate on the current effects of P\&R by providing new evidence which fully assesses the VMT effects of a scheme, as is necessary before looking at the alternative ways that car-bus interchange may be used.

As such, the following section outlines the current evidence base on the effects of $P \& R$, after which the potential novel concepts of car-bus interchange are outlined and the details of the method employed for this research described. The paper then turns to look at $\mathrm{P} \& \mathrm{R}$ in the particular context of the city of Cambridge, UK, where its current VMT effects are highlighted, followed by an estimate of the VMT effects of alternative concepts of car-bus interchange.

\section{$2 \quad$ Evidence of traffic effects}

While policymakers generally wish to intercept the motorist who would otherwise make their trip entirely by car to P\&R, user surveys of P\&R schemes (Table 1) have established that this is not always the case. In most cases and for the majority of users, it is using the car for the whole trip that is the alternative means of access to P\&R host centres. Yet public transport is also the alternative for a significant proportion of users. These trips are particularly concerning since a car trip is induced for access to P\&R. The users who would not travel to the centre include both those who would make no trip (whose VMT is completely new) and those who would travel elsewhere (whose VMT change will depend on the alternative destination).

After uncertainty over the effects of P\&R, the UK government commissioned a study looking in detail at the VMT impacts of eight schemes (WSA, 1998). It estimated the distance that would be travelled by users in the absence of $P \& R$ and that travelled to access the P\&R service and compared the two. It found that, as shown in column $I$ of Table 1, the schemes studied reduced the VMT of users in all cases. Yet the study had its shortcomings. The VMT estimates were based on the users that both arrived at the site by car and would otherwise use the car to access their destination. Furthermore, the VMT of P\&R buses was not included which is, of course, not benign. Parkhurst (1999) revaluated the findings of the study by including in the VMT estimates that of P\&R buses using a scaling factor of 2.5 to reflect the greater size, weight and emissions of the bus compared to the car. Even without the VMT of the non-motorist (those who accessed the site by means other than the car or would, in the absence of P\&R, not use the car), he showed that in three out of the eight cases, P\&R resulted in a VMT increase, as shown in column $J$ of Table 1. 
Table 1 Evidence on alternative mode of P\&R users and VMT effects

Source

WSA (1998)

Hewett and Davis (1996)

EHTF (2000)

WSA (1998)

Jones (1994)

WSA (1998)

Pickett and Gray (1996)

Pickett and Gray (1996)

WSA (1998)

Pickett and Gray (1996)

Parkhurst and Stokes (1994)

White (1977)

WSA (1998)

WSA (1998)

SYPTE (1995)

Pickett and Gray (1996)

WSA (1998)

Cooper (1993)

Parkhurst and Stokes (1994)

WSA (1998)
Centre

Day

Sample

$\mathrm{f} \quad \mathrm{g}$

h

VMT change

miles)

Change

minus car-

Would Per parker equivalent

not who would bus VMT

$\begin{array}{lllll} & & & \text { transport } & \text { Car } \\ \text { Brighton } & \text { Mon-Fri } & 220 & 41 & 26 \\ & \text { Thurs } & 674 & 40 & 54 \\ \text { Bristol } & \text { Sat } & 902 & 18 & 70 \\ & \text { Mon-Fri } & 651 & 22 & 71 \\ \text { Bristol } & \text { Sat } & 1211 & 14 & 80 \\ \text { Cambridge } & \text { Mon-Fri } & 204 & 24 & 39 \\ \text { Chester } & \text { Mon/Sat } & 124 & 14 & 60 \\ \text { Coventry } & \text { Mon-Fri } & 208 & 21 & 50 \\ \text { Maidstone } & \text { Mon-Sat } & 1000 & 15 & 66 \\ \text { Norwich } & \text { Mon-Sat } & 1000 & 12 & 78 \\ \text { Norwich } & \text { Mon-Fri } & 204 & 29 & 53 \\ \text { Nottingham } & \text { Mon-Sat } & 1000 & 25 & 59 \\ & \text { Fri } & 741 & 31 & 33 \\ \text { Oxford } & \text { Sat } & 1000 & 20 & 43 \\ & \text { Tues/Thurs } & 208 & 30 & 57 \\ \text { Oxford } & \text { Sat } & 207 & 22 & 68 \\ \text { Plymouth } & \text { Mon-Fri } & 208 & 32 & 47 \\ \text { Reading } & \text { Mon-Fri } & 220 & 31 & 43 \\ \text { Sheffield } & \text { Thurs/Sat } & 176 & - & - \\ \text { Shrewsbury } & \text { Mon-Sat } & 1000 & 11 & 67 \\ \text { Shrewsbury } & \text { Mon-Fri } & 205 & 18 & 53 \\ \text { York } & \text { N/A }{ }^{3} & 154 & 35 & 59 \\ & \text { Fri } & 288 & 26 & 54 \\ \text { York } & \text { Sat } & 310 & 9 & 65 \\ \text { York } & \text { Mon-Fri } & 221 & 26 & 57 \\ & & & & \end{array}$

travel drive (2) (3)

P\&R trav

$-2.5$

$-1.38$

$-0.93 \quad 0.63$

1.09

$-1.03 \quad 1.09$

- -

$-2.15 \quad 0.14$

- $\quad-$

$-$

$-$

$-2.92 \quad-1.58$

$-5.31-4.05$

- $\quad-$

$-$

$-3.18-2.34$

$-\quad-$

$-$

$-2.03-0.67$
- 
As outlined above, the evidence has suggested that some current P\&R schemes may have a counterproductive effect in terms of VMT. Yet the model of P\&R that currently predominates in the UK has changed very little since the first uses of $P \& R$ over 40 years ago. Nevertheless, by changing the way in which P\&R is designed, it may possible to propose new concepts of car-bus interchange. The characteristics of relevance include such things as the frequency of bus services, the distance between the P\&R site and the host city and the provision of on-site facilities. The alternative concepts of interchange are shown in Figure 1 and are derived from the literature (namely Parkhurst, 2000 for the Link and Ride concept), a scoping study of experts in the field (Meek et al, 2009) and from simply changing the characteristics within P\&R.

Figure 1 Alternative interchange concepts

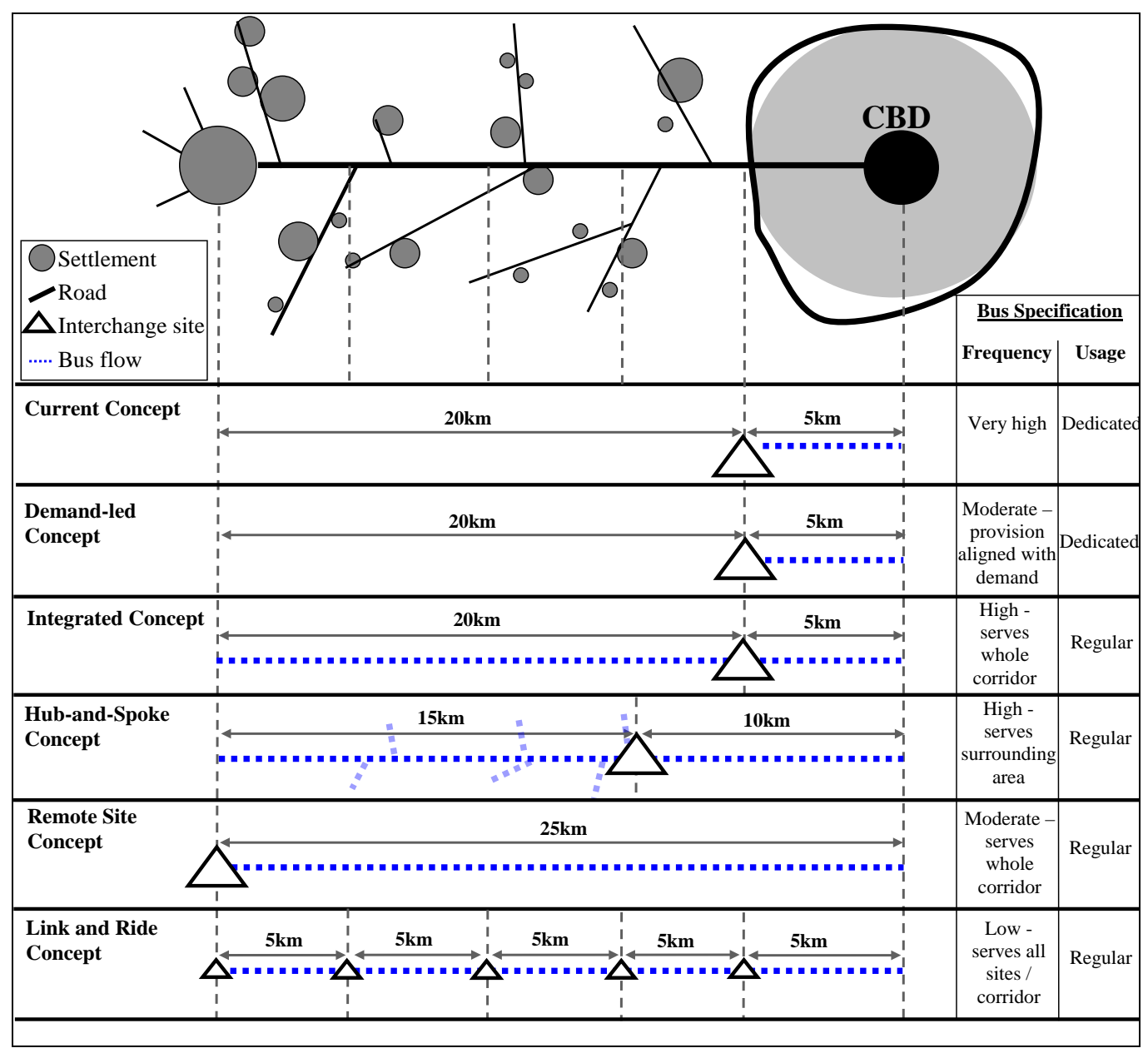

Fundamentally, the concepts consist of the following:

- $\quad$ Because the high frequency of P\&R buses in some cases increases the VMT travelled by users in the Demand-led concept bus frequency is reduced to more closely reflect demand. While this may increase the wait time and therefore the attractiveness of the service, it would increase mean load factors on P\&R buses and therefore the resultant VMT of users. 
- The Integrated concept uses conventional bus services for P\&R operation. This aims to attract conventional bus users without the need for accessing the service by car, thereby increasing load factors and reducing public transport abstraction. The bus service may start farther from the centre than the site and pass it, en route to the city centre.

- The Hub and Spoke concept proposes the use of small, feeder services for the interchange site. This is similar to the Integrated concept although smaller vehicles may be used, operation a wide range of routes. This aims to both reduce public transport abstraction and stimulate its overall use.

- The Remote Site concept extends the portion of the interchange trip made by public transport which reducing the access distance. It would thus be beneficial in this instance to locate the site as close as possible to clusters of user origins.

- In the Link and Ride concept, a chain of smaller interchange sites are provided along the host centre's access corridor to intercept the motorist earlier in their journey, while the sites are served by bus services that are available to the walk-on user.

Of course, these concepts are largely theoretical. There are thus few examples of how they may influence the VMT of users. It should be noted that there are some elements of the concepts in operation in reality, such as two long-range services in Scotland. The Ferrytoll P\&R serves Edinburgh and Ellon serves Aberdeen, operating from approximately 13 miles and 17 miles away from their host cities respectively. There is unfortunately no evidence on their VMT effects. Even so, Parkhurst (1999), who presented the Link and Ride concept, provided an estimation of its likely VMT effects based on a series of assumptions and empirical data. He suggested that the concept could reduce the VMT of its users by a mean of 9.4 miles per return trip.

\section{$4 \quad$ Method}

This paper aims to provide a comprehensive assessment of the current VMT effects of P\&R and how the alternative concepts would affect this. To this end, a survey of P\&R users was carried out in the city of Cambridge (UK) in February 2009. Cambridge is situated in the east of England, approximately 60 miles from London. It is relatively free-standing in economic terms and it is known internationally for its University and concentration of high-technology research and industry. Cambridge was selected because it is an extreme case in that its P\&R scheme is particularly well developed. P\&R has evolved since the 1980 s and the city is widely considered as hosting one of the most successful UK P\&R schemes, which currently consists of five sites (located in an approximate ring around the city), around 5000 spaces and attracts over two million return trips per year (Cambridgeshire County Council, 2008).

The survey was used to collect such things as users' home postcodes, alternative travel behaviour (secondchoice mode) and the details of P\&R travel. A questionnaire was handed to each user upon boarding the bus for their outbound journey. Instructions were provided to hand-in the questionnaire upon returning to the site, where they were collected. The response rates for each of the sites are shown in Table 2. 
Table 2 Response rates

$\begin{array}{lllllll} & \text { TRUM } & \text { NEWMRD } & \text { MILTON } & \text { BABRD } & \text { MADRD } & \text { Total } \\ \text { Users } & 638 & 739 & 762 & 1149 & 755 & 4043 \\ \text { Questionnaires distributed } & 611 & 728 & 721 & 1133 & 732 & 3925 \\ \text { Returned-all } & 208 & 232 & 138 & 362 & 313 & 1253 \\ \text { Returned-valid } & 197 & 230 & 133 & 355 & 301 & 1216 \\ \text { Valid Response (\%) } & 30.9 & 31.1 & 17.5 & 30.9 & 39.9 & 30.1 \\ \text { Returned incl. p/code } & 179 & 220 & 129 & 336 & 284 & 1148 \\ \text { P/code response (\%) } & 28.1 & 29.8 & 16.9 & 29.2 & 37.6 & 28.4\end{array}$

The data collected by the survey was used to estimate: first, the VMT resulting from alternative travel behaviour of users (if P\&R were unavailable); second, the VMT of current P\&R behaviour; and third, the VMT of alternative concepts.

For alternative behaviour:

- Car VMT was divided equally between all car occupants to either Cambridge or the alternative destination;

- Users making no trip or a trip by a green mode were assigned 0 VMT;

- For those who would use conventional bus services, a car-equivalent scaling factor of 2.5 was applied to the bus mileage between origin and destination, to account for the more significant traffic impacts of the generally single-decker conventional bus fleet. The load factor of these buses was assumed to be 13.7, derived from local data (Cambridgeshire County Council, 2007);

- The rail VMT was derived using the ArcGIS rail network. A passenger rail mile is assumed to be 0.5 of a car mile (ATOC, 2004). Users travelling farther than one mile to the train station were assumed to get a lift to the station thus giving car occupancy of 2. For users travelling less than one mile to the station, access on foot is assumed.

For P\&R travel behaviour:

- Access trips were treated the same as alternative behaviour;

- The bus portion of trips was estimated using actual bus operations, including the bus circuits per day, the bus route distances, a bus scaling factor of 3 (P\&R buses are double-decker) and the total number of users on the survey days.

For alternative interchange concepts:

- Components of current P\&R sites were substituted were necessary, such as the location of P\&R sites and bus routes. Users' origins were unchanged; 
- Using ArcGIS is was possible to select the optimum location for P\&R sites - those which minimised total access distance for instance - where these were changed.

\section{$5 \quad$ Results - current traffic effects}

Figure 2 shows the origins of P\&R users. Using these data, alongside the P\&R arrival mode and alternative mode, the VMT of alternative travel behaviour was estimated as shown in Table 3. Clearly the bus users would have a much lower mean VMT than those travelling by car. Yet the VMT for train users is much higher because of the greater distances travelled by those using this mode. With the exception of those who would get a lift, the travellers that would use the car have a relatively similar mean VMT. Interestingly, those that would travel elsewhere would have a slightly higher VMT in most cases than those that would still travel to Cambridge. This runs counter to the notion that P\&R induces longer trips by lowering the generalised cost of travel but clearly there is some reliance on $P \& R$ as a means to get to Cambridge and in its absence, users may travel farther to a destination with a similar offering.

The VMT resulting from the use of P\&R includes that from both access and bus trips, shown in Table 4. The mean distance travelled to P\&R sites was 15.38 miles. With the exception of Trumpington where a shuttle service operates between the site and the city centre, the other sites form pairs between which buses operate. Whilst all bus routes serve the Grafton Shopping Centre, those from Newmarket Road and Milton exclude this stop before 09:00. The bus VMT per user allocated to Trumpington users is by far greater than the other sites. This is simply because the 5.4 mile distance from the site to the city centre is longer than the equivalent distances for the other sites.

Figure 2 User origins

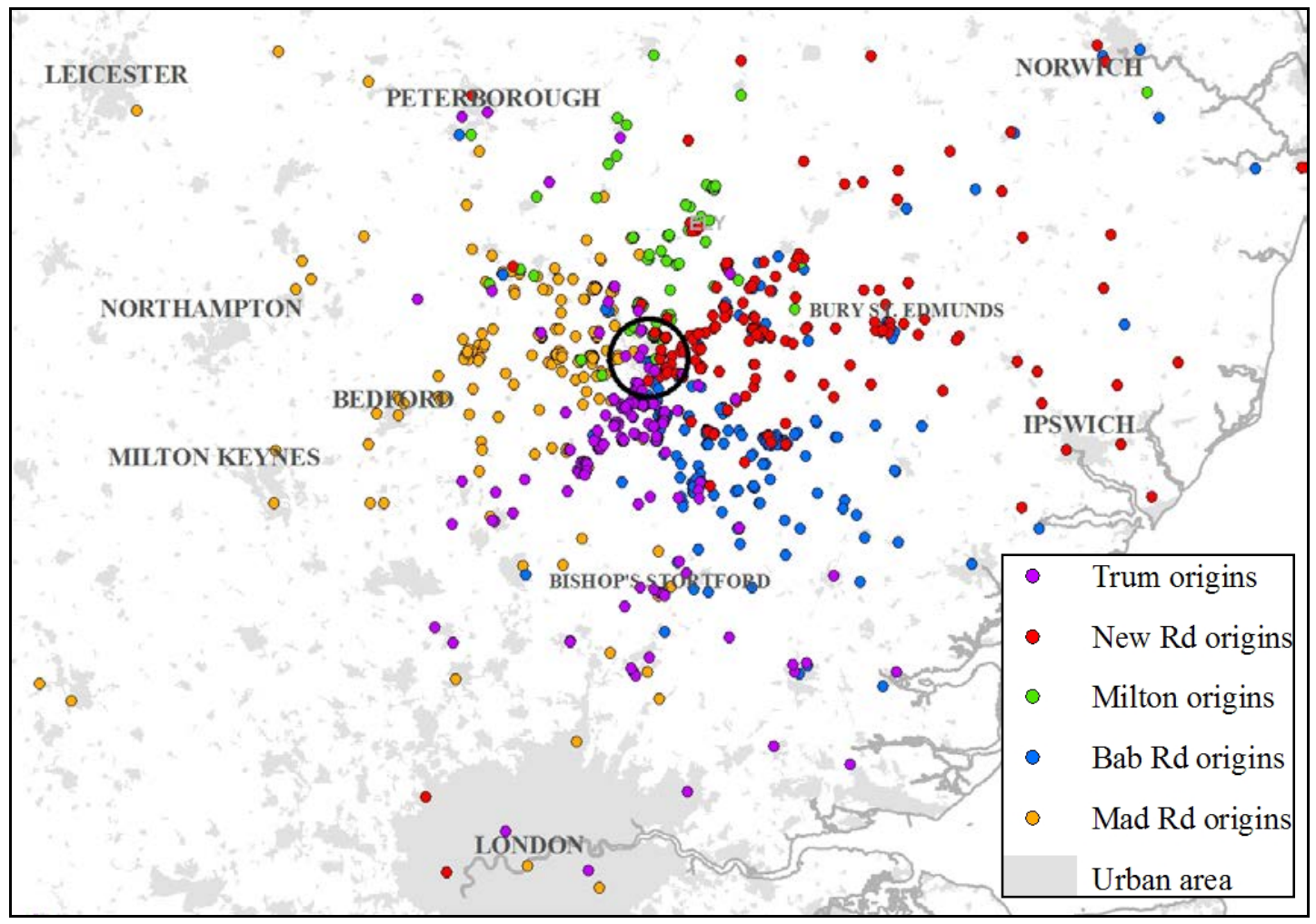


Table 3 VMT of alternative travel behaviour

\begin{tabular}{|c|c|c|c|c|c|c|c|}
\hline & 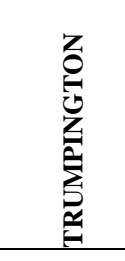 & 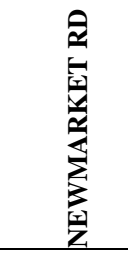 & 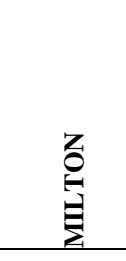 & 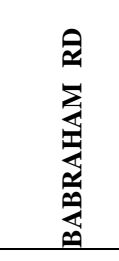 & 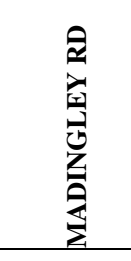 & $\bar{z}$ & $\begin{array}{l}0 \\
0 \\
0 \\
0 \\
0 \\
0 \\
0 \\
0\end{array}$ \\
\hline Bus & 3.63 & 5.27 & 3.2 & 4.67 & 4.83 & 4.45 & 30.4 \\
\hline Train & 15.51 & 34.05 & 17.54 & 19.17 & 18.6 & 21.72 & 6 \\
\hline Car - pay for public parking & 38.07 & 37.91 & 41.56 & 36.74 & 35.97 & 37.41 & 34.6 \\
\hline Car - use free public parking & 53.89 & 35.21 & 32.83 & 43.84 & 39.24 & 40.46 & 4 \\
\hline Car - use free private parking & 34.29 & 42.82 & 19.42 & 27.92 & 33.48 & 31.28 & 10.9 \\
\hline Car - get a lift & 6.19 & 25.57 & 12.05 & 10.95 & 17.97 & 17.13 & 0.9 \\
\hline Walk/Cycle & 0 & 0 & - & 0 & 0 & 0 & $2.2 / 1.7$ \\
\hline Make no trip & 0 & 0 & 0 & 0 & 0 & 0 & 4.8 \\
\hline Travel elsewhere & 34.87 & 43.12 & 44.15 & 44.45 & 31.46 & 39.99 & 4.4 \\
\hline All (mean) & 21.63 & 24.82 & 18.52 & 23.68 & 22.28 & 22.66 & \\
\hline Pax/day & 638 & 739 & 755 & 762 & 1149 & 4043 & \\
\hline Total VMT (day) & 13802.15 & 18345.11 & 13984.51 & 18046.52 & 25604.54 & 91599.17 & \\
\hline
\end{tabular}

Table 4 P\&R VMT

\begin{tabular}{|c|c|c|c|c|c|c|c|}
\hline & 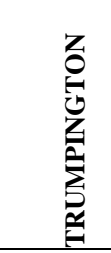 & 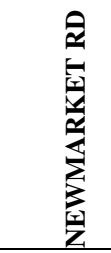 & 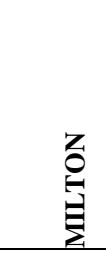 & 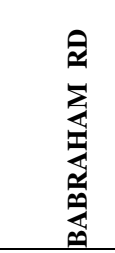 & 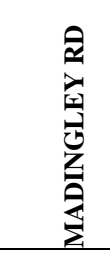 & $\equiv$ & 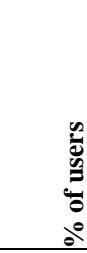 \\
\hline \multicolumn{8}{|l|}{ ACCESS VMT } \\
\hline Car driver alone & 32.61 & 31.66 & 22.72 & 27.99 & 29.02 & 29.09 & 64 \\
\hline Car driver with 1 pax & 11.65 & 20.66 & 15.79 & 16.5 & 18.55 & 17.05 & 22.9 \\
\hline Car driver with 2 pax & 12.63 & 10.09 & 48.75 & 15.98 & 8.29 & 15.14 & 1.8 \\
\hline Car driver with 3 pax & 1.54 & 22.24 & & 8.27 & 38.88 & 16.9 & 0.6 \\
\hline Car driver with 4 pax & & 5.31 & & & & 5.31 & 0.1 \\
\hline Car passenger & 12.2 & 22.83 & 16.49 & 12.08 & 45.32 & 18.54 & 5 \\
\hline Car (dropped off) & 13.45 & 2.61 & 9.23 & 6.9 & 9.58 & 9.1 & 1.9 \\
\hline Walked & 0 & 0 & 0 & & 0 & 0 & 3.4 \\
\hline \multicolumn{8}{|l|}{ BUS VMT } \\
\hline Outbound (site-site) trip & 5.4 & 6.1 & 6.1 & 7.4 & 7.4 & - & \\
\hline O/b trip excl. Grafton & $\mathrm{n} / \mathrm{a}$ & 5.2 & $\mathrm{n} / \mathrm{a}$ & 7.1 & $\mathrm{n} / \mathrm{a}$ & - & \\
\hline Circuits/day & 150 & 74 & 75 & 79 & 75 & - & \\
\hline Total route miles & 810 & 440.6 & 457.5 & 581 & 555 & - & \\
\hline Bus VMT (*3 scaling) & 2430 & 1321.8 & 1372.5 & 1743 & 1665 & - & \\
\hline Bus VMT per pax & 3.8 & 1.8 & 1.8 & 1.4 & 2.3 & - & \\
\hline All (mean) & 27.09 & 28.93 & 19.88 & 26.12 & 27.03 & 26.33 & \\
\hline Total VMT (day) & 17283.3 & 21376.4 & 15009.7 & 19905.6 & 31059.5 & 106469.4 & \\
\hline
\end{tabular}

The total alternative VMT of all daily users is 91,599 miles, which is 14,870 miles less than that resulting from P\&R use. Table 5 disaggregates the VMT changes for sites and alternative behaviour. VMT savings result from users with the car alternative, with the exception of most of those who would get a lift and the Trumpington users that would use free parking. This shows that any detouring to access P\&R sites is 
insufficient to result in net VMT increases for these users. Yet for the P\&R users that would use the bus, train, a green mode or not make a trip generally outweigh the VMT savings made by car users. Across the sites, the mean VMT increase is lower at Milton with 1.36 due to the high number of users accessing P\&R on foot as well as the relatively short distance travelled to the site by car drivers. The similarly lower mean increase for Babraham Road users can be attributed to the lower mean P\&R access VMT. Nevertheless, for the 1148 users in the sample, P\&R increased VMT by a total of 4,222 miles on the survey days. When this is scaled to all survey day P\&R users and combined, $P \& R$ can be said to have increased VMT in Cambridge by 14,870 miles.

\section{$6 \quad$ Results - traffic effects of alternative concepts}

The results of estimating the VMT effects of the alternative concepts are shown in Table 6 and are given as scenarios for ease of reference. Most of these are based on the original choice of site by users although some scenarios assumed that users may opt for the site closest to them in different circumstances, or, it may difficult to retain original site choice given a change in the number of sites. The number of bus users changes where additional passengers are added to the service or different site choice is assumed.

Table 5 VMT Change

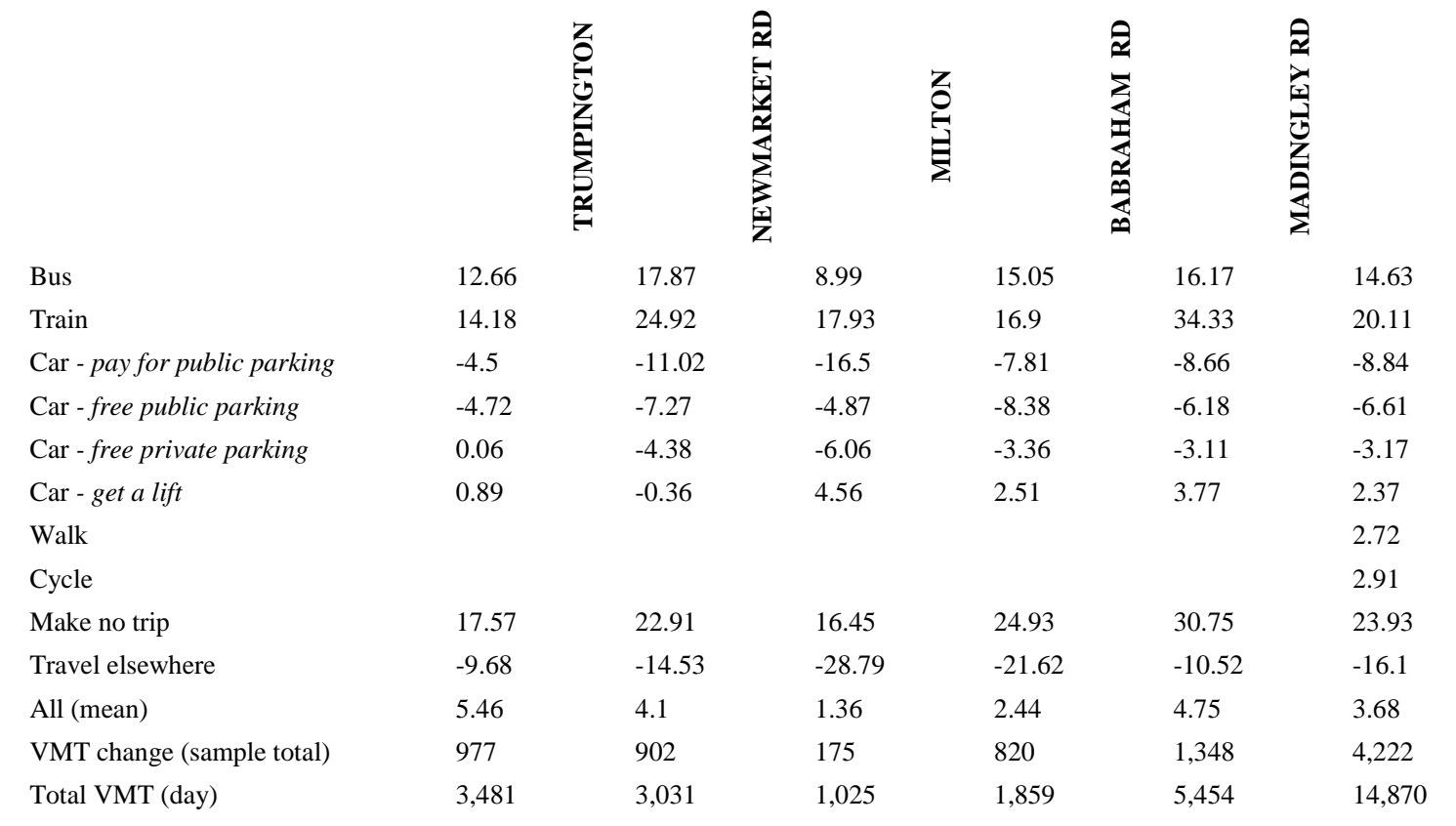

The Demand-led concept reduces the frequency of P\&R buses to 20 minutes between 10:00 and 16:00 (scenario 2). Whilst this removes half of the bus VMT in this period, the overall effect on VMT is relatively small. Mean VMT savings are increased by only 0.52 miles compared to the current concept, although this does equate to 2116 miles per day for all P\&R users. The model was also run for closest site allocations (scenario 3) whilst scenario 4 reduces bus frequency even further to 20 minutes at all times, resulting in a decrease in mean VMT to 2.71. 
Thus, even with dramatic reductions in frequency, the proportion of it within total VMT is sufficiently small to make an insignificant difference. The occurrence of interchange resulting in a higher VMT than alternative behaviour thus continues to be related to the much lower VMT that would result from alternative behaviour. The previous subsections would indicate that this is largely down to the abstraction of passengers from public transport, which the following (Integrated) concept seeks to address.

With the Integrated concept, bus routes begin from much farther out than the P\&R sites. The routes selected, shown in Figure 3, were designed in ArcGIS to minimise the distance travelled to routes and are based on clusters of user origins or the interception of main trunk routes. A full length bus route is operated every 30 minutes, with other P\&R service operating as normal. The assumption made for the initial Integrated concept scenario (5), was that users residing within one mile of a bus stop would walk to access the service. For users living beyond a mile, usual (current) access behaviour is assumed. The results of this model suggest that VMT is reduced by around one third of that of the Current concept, to 2.54 miles. The reduction of this walking distance to 0.5 (scenario 7) results in a greater VMT increase than the current concept.

Figure 3 Integrated concept

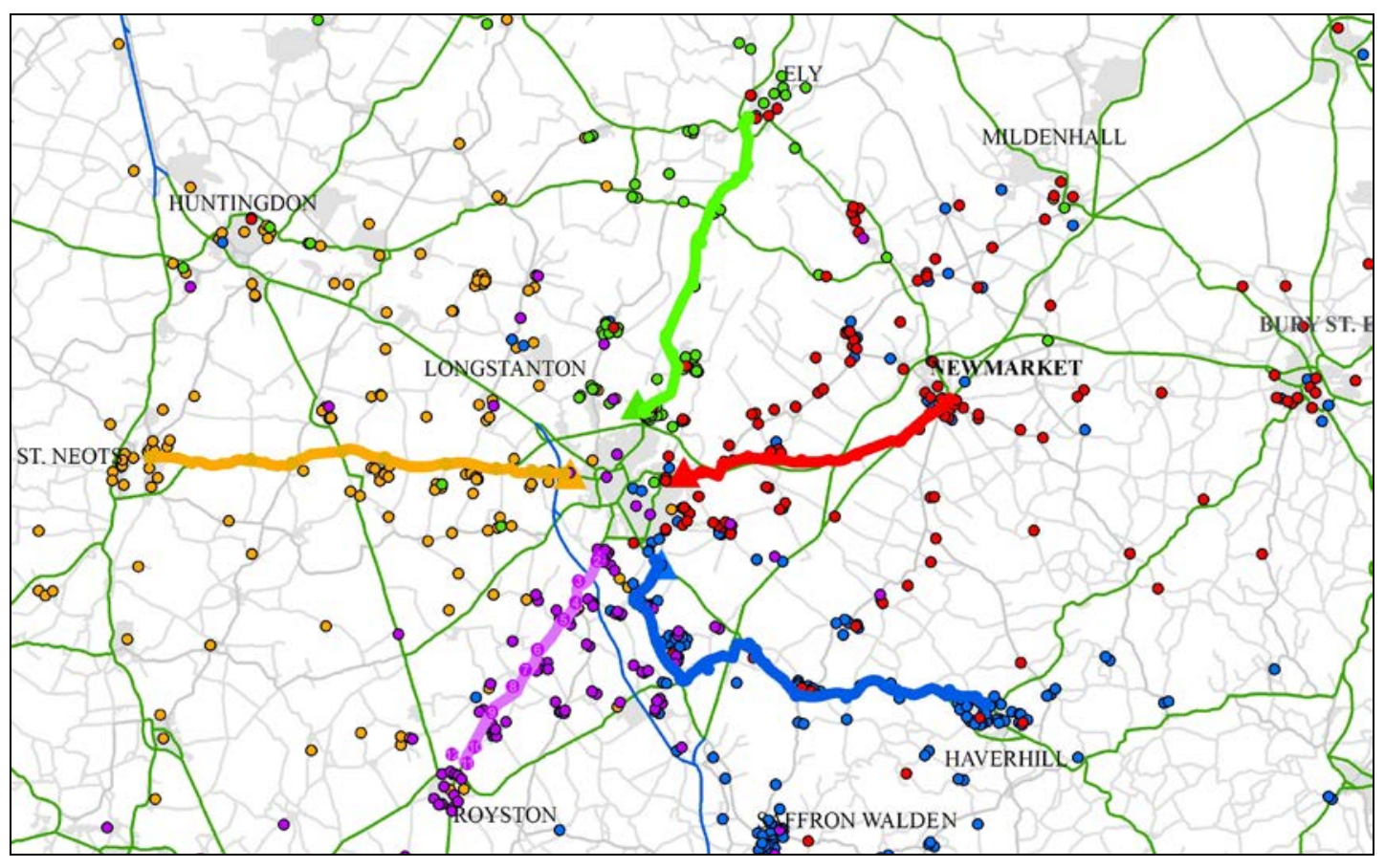

There is a possibility of course, especially if stage bus services are integrated with those serving the P\&R, that additional users would be attracted to the service. Thus, scenario 8 inputs 27.4 passengers per site per hour which results in a lower mean VMT increase than the current concept of 1.41. 
Table 6 VMT effects of alternative concepts

\begin{tabular}{|c|c|c|c|c|c|c|c|c|c|c|c|c|c|}
\hline \multirow{3}{*}{$\begin{array}{l}\text { Concept } \\
\text { Scenario } \\
\text { Site choice (original/closest) } \\
\text { Additional stage bus pax } \\
\text { (site/hour) }\end{array}$} & \multirow{3}{*}{\begin{tabular}{l} 
Current \\
\multicolumn{1}{|c|}{1} \\
Orig
\end{tabular}} & \multicolumn{3}{|c|}{ Demand-led } & \multicolumn{4}{|c|}{ Integrated } & \multicolumn{5}{|c|}{ Hub and Spoke } \\
\hline & & 2 & 3 & 4 & 5 & 6 & 7 & 8 & 9 & 10 & 11 & 12 & 13 \\
\hline & & Orig & $\begin{array}{l}\text { Clos } \\
-\end{array}$ & $\begin{array}{l}\text { Orig } \\
-\end{array}$ & $\begin{array}{l}\text { Orig } \\
-\end{array}$ & $\begin{array}{l}\text { Clos } \\
-\end{array}$ & $\begin{array}{l}\text { Orig } \\
-\end{array}$ & $\begin{array}{l}\text { Orig } \\
27.4\end{array}$ & $\begin{array}{l}\text { Orig } \\
-\end{array}$ & $\begin{array}{l}\text { Clos } \\
-\end{array}$ & $\begin{array}{l}\text { Orig } \\
-\end{array}$ & $\begin{array}{l}\text { Orig } \\
-\end{array}$ & $\begin{array}{l}\text { Orig } \\
27.4\end{array}$ \\
\hline \multicolumn{14}{|l|}{ Daily P\&R bus users } \\
\hline - Trumpington & 638 & 638 & 550 & 638 & 638 & 550 & 638 & 1005 & 638 & 768 & 638 & 638 & 1005 \\
\hline - Newmarket Rd & 739 & 739 & 908 & 739 & 739 & 908 & 739 & 1095 & 739 & 859 & 739 & 739 & 1095 \\
\hline - Milton & 762 & 762 & 857 & 762 & 762 & 857 & 762 & 1146 & 762 & 871 & 762 & 762 & 1146 \\
\hline - Babraham Rd & 1149 & 1149 & 1054 & 1149 & 1149 & 1054 & 1149 & 1512 & 1149 & 882 & 1149 & 1149 & 1512 \\
\hline - Madingley Rd & 755 & 755 & 674 & 755 & 755 & 674 & 755 & 1117 & 755 & 664 & 755 & 755 & 1117 \\
\hline - Site 6 & & & & & & & & & & & & & \\
\hline Walking proximity & - & - & - & - & 1 & 1 & 0.5 & 1 & 1 & 1 & 1 & 0.5 & 1 \\
\hline \multicolumn{14}{|l|}{ P\&R operation } \\
\hline Bus frequency <10:00 & 10 & 10 & 10 & 20 & 10 & 10 & 10 & 10 & 10 & 10 & 15 & 10 & 10 \\
\hline Bus frequency 10:00-16:00 (mins) & 10 & 20 & 20 & 20 & 10 & 10 & 10 & 10 & 10 & 10 & 15 & 10 & 10 \\
\hline Bus frequency 16:00-18:00 (mins) & 10 & 10 & 10 & 20 & 10 & 10 & 10 & 10 & 10 & 10 & 15 & 10 & 10 \\
\hline Bus frequency $>18: 00$ (mins) & 20 & 20 & 20 & 20 & 20 & 20 & 20 & 20 & 20 & 20 & 20 & 20 & 20 \\
\hline Number of P\&R/feeder routes & 5 & 5 & 5 & 5 & 5 & 5 & 5 & 5 & 10 & 10 & 10 & 10 & 10 \\
\hline Number of interchange sites & 5 & 5 & 5 & 5 & 5 & 5 & 5 & 5 & 5 & 5 & 5 & 5 & 5 \\
\hline \multicolumn{14}{|l|}{ VMT Results } \\
\hline Scenario VMT (sample total) & 30213 & 29662 & 28501 & 29145 & 29512 & 27806 & 31021 & 28229 & 29365 & 25959 & 28866 & 30122 & 26136 \\
\hline Scenario VMT (mean) & 26.33 & 25.84 & 24.83 & 25.39 & 25.71 & 24.22 & 27.02 & 24.59 & 25.58 & 22.61 & 25.14 & 26.24 & 22.77 \\
\hline Bus VMT (\% of scenario VMT) & 7.85 & 6.21 & 6.42 & 4.42 & 14.15 & 15.23 & 13.46 & 10.13 & 34.48 & 39.90 & 33.35 & 33.62 & 26.39 \\
\hline VMT change (sample total) & & 4183 & 3632 & 2471 & 3115 & 3482 & 1776 & 4991 & 2199 & 3335 & -71 & 2836 & 4092 \\
\hline VMT change (mean) & 3.68 & 3.16 & 2.15 & 2.71 & 2.54 & 1.05 & 3.85 & 1.41 & 2.40 & -0.56 & 1.97 & 3.07 & -0.41 \\
\hline - Trumpington & 5.46 & 4.42 & 1.64 & 3.56 & 6.29 & 3.70 & 7.26 & 3.94 & 5.64 & -0.39 & 4.47 & 5.82 & 2.44 \\
\hline - Newmarket Rd & 4.10 & 3.66 & 2.03 & 3.52 & 3.10 & 0.63 & 4.06 & 2.17 & 4.51 & -0.49 & 4.23 & 6.37 & 0.90 \\
\hline - Milton & 1.36 & 0.83 & 2.72 & 0.02 & 1.01 & 2.47 & 1.48 & -0.24 & 3.07 & 2.84 & 2.43 & 3.46 & -0.90 \\
\hline - Babraham Rd & 2.44 & 2.09 & 1.99 & 1.76 & 0.36 & -0.90 & 2.59 & -0.58 & -3.15 & -6.57 & -3.38 & -2.67 & -4.31 \\
\hline - Madingley Rd & 4.75 & 4.31 & 2.43 & 3.90 & 3.01 & 1.39 & 4.11 & 2.34 & 5.00 & 3.16 & 4.75 & 5.38 & 1.62 \\
\hline - Site 6 & & & & & & & & & & & & & \\
\hline VMT change (day total) & 13935 & 11819 & 8815 & 9857 & 9750 & 4713 & 14836 & 7797 & 9420 & -1949 & 7534 & 12057 & -2308 \\
\hline
\end{tabular}


Table 6 continued

\begin{tabular}{|c|c|c|c|c|c|c|c|c|c|}
\hline \multirow{3}{*}{$\begin{array}{l}\text { Concept } \\
\text { Scenario } \\
\text { Site choice (original/closest) } \\
\text { Additional stage bus pax } \\
\text { (site/hour) }\end{array}$} & \multicolumn{5}{|c|}{ Remote Site } & \multicolumn{4}{|c|}{ Link and Ride } \\
\hline & 14 & 15 & 16 & 17 & 18 & 19 & 20 & 21 & 22 \\
\hline & $\begin{array}{l}\text { Orig } \\
- \\
\end{array}$ & $\begin{array}{l}\text { Clos } \\
- \\
\end{array}$ & $\begin{array}{l}\text { Orig } \\
- \\
\end{array}$ & $\begin{array}{l}\text { Orig } \\
27.4 \\
\end{array}$ & $\begin{array}{l}\text { Orig } \\
- \\
\end{array}$ & $\begin{array}{l}\text { Clos } \\
- \\
\end{array}$ & $\begin{array}{l}\text { Clos } \\
- \\
\end{array}$ & $\begin{array}{l}\text { Clos } \\
27.4 \\
\end{array}$ & $\begin{array}{l}\text { Clos } \\
- \\
\end{array}$ \\
\hline \multicolumn{10}{|l|}{ Daily P\&R bus users } \\
\hline - Trumpington & 638 & 983 & 638 & 1005 & 638 & 465 & 465 & 727 & 465 \\
\hline - Newmarket Rd & 739 & 735 & 739 & 1095 & 739 & 845 & 845 & 1107 & 845 \\
\hline - Milton & 762 & 938 & 762 & 1146 & 762 & 1067 & 1067 & 1329 & 1067 \\
\hline - Babraham Rd & 1149 & 850 & 1149 & 1512 & 1149 & 190 & 190 & 452 & 190 \\
\hline - Madingley Rd & 755 & 537 & 755 & 1117 & 755 & 440 & 440 & 702 & 440 \\
\hline - Site 6 & & & & & & 1035 & 1035 & 1297 & 1035 \\
\hline Walking proximity & 1 & 1 & 1 & 1 & 0.5 & 1 & 1 & 1 & 0.5 \\
\hline \multicolumn{10}{|l|}{ P\&R operation } \\
\hline Bus frequency $<10: 00$ & 10 & 10 & 15 & 10 & 10 & 12 & 18 & 12 & 12 \\
\hline Bus frequency 10:00-16:00 (mins) & 10 & 10 & 15 & 10 & 10 & 12 & 18 & 12 & 12 \\
\hline Bus frequency 16:00-18:00 (mins) & 10 & 10 & 15 & 10 & 10 & 12 & 18 & 12 & 12 \\
\hline Bus frequency $>18: 00$ (mins) & 20 & 20 & 20 & 20 & 20 & 24 & 24 & 24 & 24 \\
\hline Number of P\&R/feeder routes & 5 & 5 & 5 & 5 & 5 & 6 & 6 & 6 & 6 \\
\hline Number of interchange sites & 5 & 5 & 5 & 5 & 5 & 25 & 25 & 25 & 25 \\
\hline \multicolumn{10}{|l|}{ VMT Results } \\
\hline Scenario VMT (sample total) & 28513 & 26002 & 26444 & 26344 & 29744 & 19459 & 17442 & 17720 & 19605 \\
\hline Scenario VMT (mean) & 24.84 & 22.65 & 23.04 & 22.95 & 25.91 & 16.95 & 15.19 & 15.44 & 17.08 \\
\hline Bus VMT (\% of scenario VMT) & 24.10 & 29.22 & 18.16 & 17.87 & 23.10 & 31.10 & 23.13 & 24.34 & 30.87 \\
\hline VMT change (sample total) & 106 & 2483 & -28 & 414 & 314 & 3714 & -6546 & -8563 & -8285 \\
\hline VMT change (mean) & 1.67 & -0.52 & -0.14 & -0.22 & 2.74 & -5.70 & -7.46 & -7.22 & -5.58 \\
\hline - Trumpington & 5.49 & 3.43 & 3.59 & 3.07 & 6.10 & -4.64 & -6.76 & -6.94 & -4.51 \\
\hline - Newmarket Rd & 1.88 & -5.47 & -0.41 & -0.48 & 2.72 & -4.54 & -6.25 & -5.75 & -4.42 \\
\hline - Milton & 1.96 & 3.85 & 0.22 & 0.05 & 2.55 & 12.17 & 13.15 & 12.75 & 11.93 \\
\hline - Babraham Rd & -2.60 & -4.25 & -3.70 & -3.50 & -0.94 & 5.69 & 2.83 & 0.72 & 5.85 \\
\hline - Madingley Rd & 4.00 & 0.12 & 1.78 & 1.66 & 5.07 & 14.12 & 16.80 & 17.12 & 14.02 \\
\hline - Site 6 & & & & & & 1.03 & -0.82 & -0.09 & 1.05 \\
\hline VMT change (day total) & 6422 & -592 & -749 & -834 & 10591 & 23053 & 30157 & 40151 & 22540 \\
\hline
\end{tabular}


The Hub and Spoke concept involves a number of rural bus routes feeding into sites (Figure 4). Feeder buses operate every 20 minutes and a scaling factor of 2.5 is applied to them, the same as single-decker fleet vehicles for the alternative behaviour estimations. Two feeder routes serve each interchange site and the shuttle element operates as it does currently. The walking proximity is assumed to be one mile initially in scenario 9 and a very large proportion of users - 39\% - reside within this distance of a feeder bus stop. Yet even with such a large proportion of walkers, the concept still induces an increase in mean VMT of 2.4 per person. Clearly, the bus VMT of the extensive feeders bring the increase; it constitutes 34\% of the VMT total in this scenario. The situation improves when the frequency of the shuttle bus element is reduced to 15 minutes as in scenario 11, yet this results in only a slightly lower mean VMT change of +1.97. It is not until additional passengers - 27.4 per hour, per site, walking to access the service - are introduced in scenario 13 that VMT savings start to be seen.

The closest site allocation is also worth consideration here. If a feeder bus service is available to passengers to access on foot, a higher proportion of users may opt for the closet service choice. In this instance, even with a 10 minutes shuttle frequency in scenario 10, a mean VMT reduction of 0.56 occurs. Nevertheless, as with the Integrated concept, the assumption of 1 mile walking proximity is unlikely to hold in all circumstances. Where a 0.5 miles proximity is assumed in scenario 12, a mean VMT increase of 3.07 is seen, although where closest site allocation is given, there is only a slight increase of 0.29 miles.

With the Remote Site concept, sites are located farther from the city than Current concept sites (Figure 5). The aim of the concept is to increase the distance travelled by the bus whilst reducing access distance. In scenario 14 there is a significant reduction in mean VMT compared to the Current concept but an increase compared to alternative behaviour still exists. As might be anticipated, where the bus frequency is reduced and additional passengers are added to bus use (scenarios 16 and 18), reductions in VMT are seen. 
Figure 4 Hub and Spoke concept

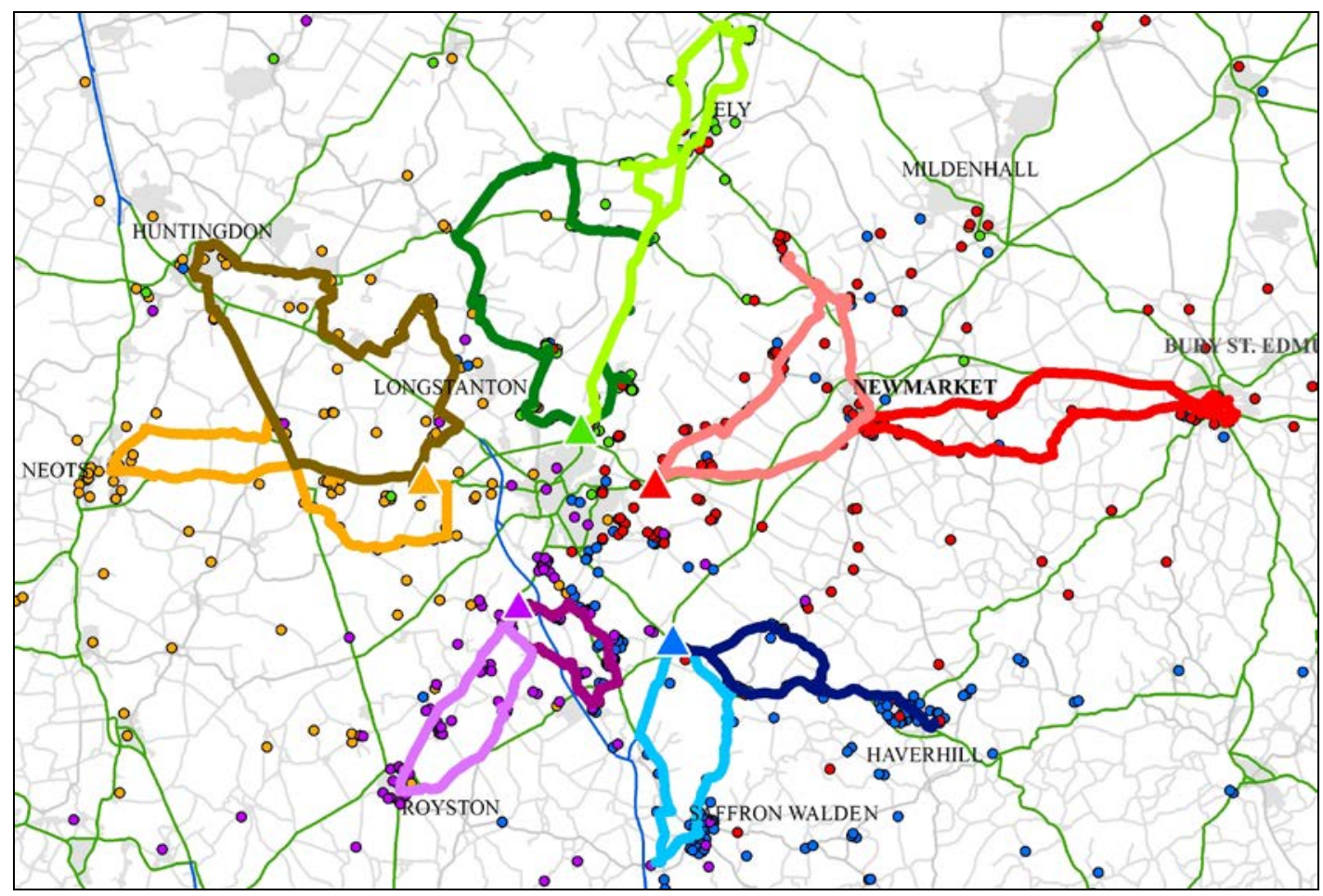

Figure 5 Remote Site concept

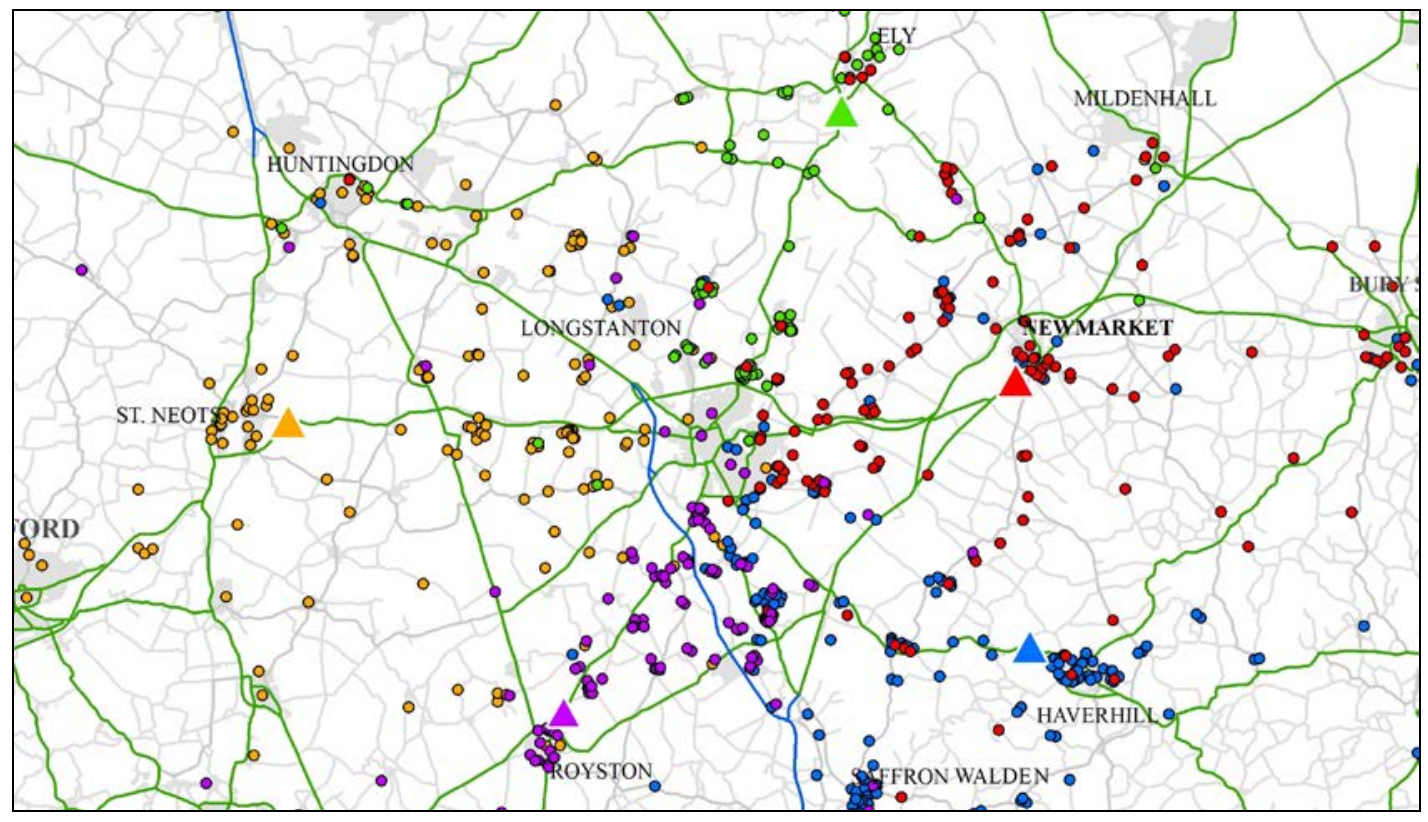

There is a great degree of variation in the difference in mean VMT change between the sites and where greater VMT results than the current concept, it is the reductions from the other remote sites that offsets the increases. One of the problems with the Current concept is that users are intercepted relatively late in their trips. The access VMT is particularly significant when it comes to those abstracted from public transport, whose access trips represent much greater additions to VMT. On the other hand, the Remote Site concept which aimed to intercept users earlier in the access trips, seemed to be limited in effectiveness because of the deviation required by some to access them, along with the greater bus VMT required to serve sites. This 
was of course exaggerated where users are assumed to remain loyal to their existing site choice. The Link and Ride concept uses multiple interchange sites located along corridors to intercept a large proportion of users early in their journeys. Furthermore, for those living very close to the corridors, bus stops are provided by the concept at approximately one mile intervals, the exact location being determined by clusters of origins.

Figure 6 Link and Ride concept

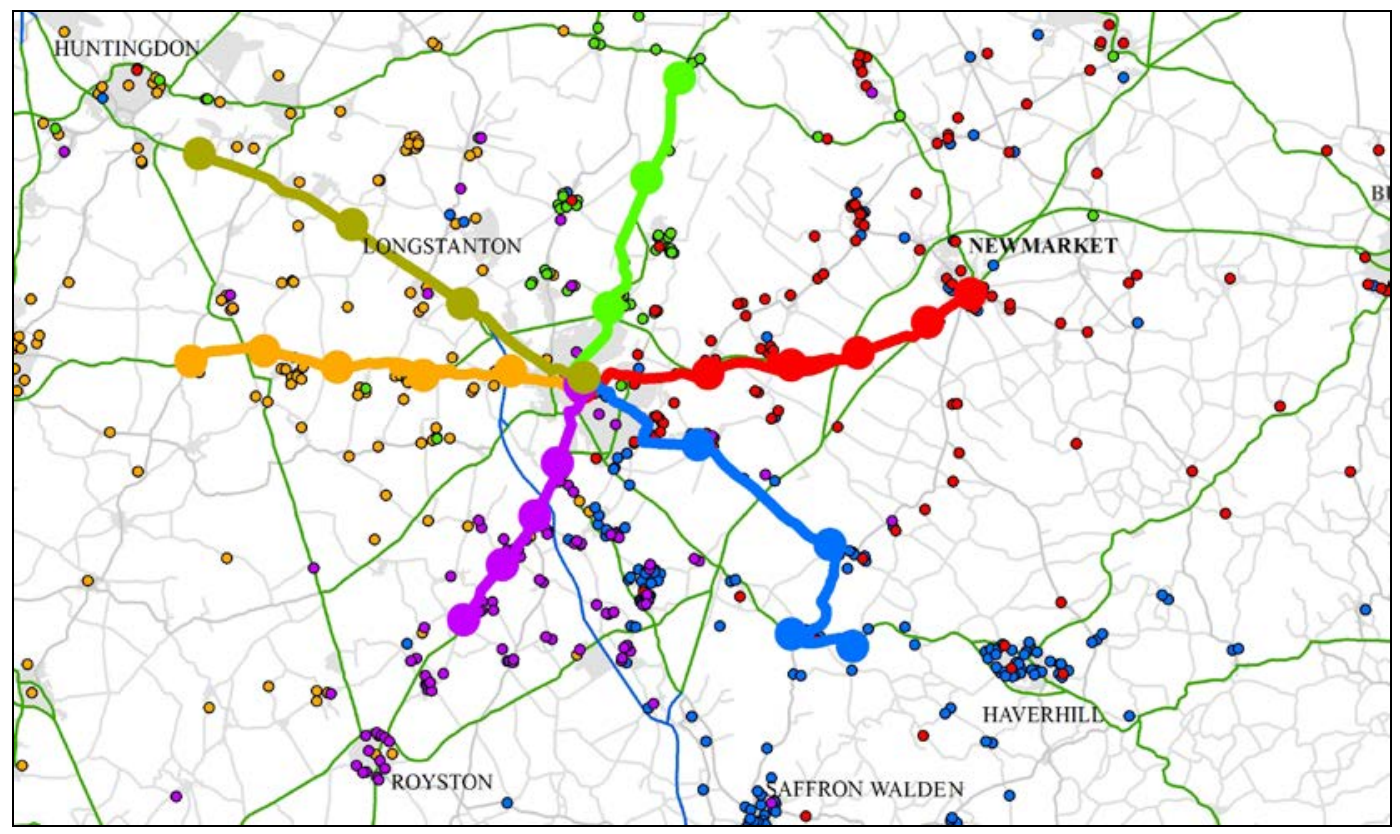

After several attempts to refine the model using the ArcGIS software, a six route format was selected (Figure 6 and scenario 19). While this concept results in significant VMT reductions, there is an increase on the Trumpington and number 6 routes (which if not used would induce fewer reductions), this is offset by the benefits of lower access VMT to the additional sites than would be made where there are a lower number of sites.

There are obviously significant reductions where additional bus passengers of two (13.7) loads per site per hour (scenario 21). This is not an implausible assumption since these services offer a reasonably long range and will duplicate some existing stage service routes. Notably, the Link and Ride concept is also calculable for closest site choice since the addition of a new route makes original site choice problematic to estimate. Furthermore, the number of services on the whole of the P\&R network is assumed to remain constant so frequency is slightly reduced when the additional site is added.

\section{Conclusions}

P\&R clearly brings distinct benefits to its users by reducing the generalised cost of travel through time or monetary savings, or through a higher perceived quality than the alternatives. Yet there are also problems. It is not only important to consider the overall VMT impacts of P\&R but also the contributory factors to 
this. These are affected by both the users that P\&R attracts, particularly the mode that they would use in the absence of P\&R, and its intrinsic VMT by buses.

Overall, evidence has shown relatively high levels of public transport abstraction compared to previous surveys. This is particularly true, it should be said, when considering the previous work on P\&R in Cambridge. This may be down to changing attitudes towards conventional public transport over time, either due to the use of $\mathrm{P} \& \mathrm{R}$ or independently.

Combining the effects of the trips abstracted from public transport, diverted or generated with the fundamental design features of P\&R, such as the VMT resulting from high bus frequency and site location, results in the total VMT impacts. The only previous work calculating VMT effects is WSA (1998) and Parkhurst (1999). Both of these authors however based their estimations on the 35\% of users who drove to the Cambridge P\&R sites and would otherwise drive to the city centre, which resulted in a decrease in VMT of 0.93 (WSA, 1998) when considering only access behaviour and an increase of 0.68 (Parkhurst, 1999) when also including bus.

This survey found a very similar proportion of users who drove to the site and would drive to the centre in the absence of $P \& R, 34.06 \%$. Yet the mean VMT change from these users is much lower than the aforementioned estimates at -2.33 . Thus, if P\&R only attracted drivers who would otherwise use the car, it would result in considerable VMT savings. Yet this is not the reality. Trips abstracted from public transport and those generated contribute significant VMT increases to the total since the access trips of these users are generally switched to the car from the bus or train and are long compared to the distance between the P\&R site and the town centre. The only exception are diverted trips since it appears that those that would be made in the absence of P\&R are longer than P\&R trips. Nevertheless, the other non-car alternative trips result in significant increases in VMT resulting in a mean VMT increase of 3.68 per user and added 14,870 miles of travel to Cambridge's roads when the sites were combined. In Cambridge at least, this estimate is significant not only because of the degree to which it suggests that P\&R is ineffective in reducing VMT but also because by including non-car alternative trips it is a particularly comprehensive assessment of the VMT effects of P\&R.

This paper not only considered existing P\&R models but also possible alternatives. Clearly the most beneficial of these is the Link and Ride concept which was shown to offer significant VMT savings. Something which has not been discussed in depth here is the resource requirements for the alternative concepts. Clearly Link and Ride is a significant departure from the current concept any may require significant resources. It may be considered a long-term solution however. The Hub and Spoke concept on the other hand is very similar to the current concept. It involves similar sites with additional feeder services. Indeed, these services may in reality be existing rural bus services. When additional passengers from these services were included in the model, VMT reductions resulted. The Hub and Spoke concept may thus offer an intermediate solution. 
ATOC, 2004. Rail and the Environment. London: ATOC.

Cambridgeshire County Council, 2007. The 2007 Traffic Monitoring Report. Cambridge:

Cambridgeshire County Council.

Cambridgeshire County Council, 2008. Cambridge Park and Ride Information Pack. Cambridge:

Cambridgeshire County Council.

Cooper, B., 1993. An Investigation into the Behaviour and Attitudes of Users of Peripheral and City

Centre Parking in York. M.Sc. Thesis. Transport Studies Group, University of Westminster.

DETR, 1998. A New Deal for Transport: Better for Everyone. Cm 3950. London: HMSO.

DETR, 2000. Transport 2010: The 10-Year Plan. London: HMSO.

DoE - Department of the Environment, 1990. This Common Inheritance. White Paper on the Environment. Cm. 1200. London: HMSO.

EHTF - English Historic Towns Forum, 2000. Bus-based Park and Ride: A Good Practice Guide. 2nd ed. Bristol: EHTF.

Hewett, B., and Davis, P., 1996. A4 Bath Road Park \& Ride, Brislington - Operation and usage characteristics. Proceedings of CPRE Avon Transport Campaign Group Park and Ride Conference. Bath, November 1996.

Jones, R., 1994. The Effect of Park and Ride on Users' Travel Behaviour. M.Sc. Thesis, Department of Engineering, University of Newcastle-Upon-Tyne, UK.

Meek, S., Ison, S., and Enoch, M., 2008. Role of bus-based park and ride in the UK: A temporal and evaluative review. Transport Reviews, 28(6), 781-803.

Meek, S., Ison, S., and Enoch, M., 2009. Stakeholder perspectives on the current and future roles of UK bus-based Park and Ride. Journal of Transport Geography, 17(6), 468-475.

Parkhurst, G., 1999. Environmental Cost-Benefits of Bus-based Park and Ride Systems. Working 
Paper 1999/4. London: ESRC Transport Studies Unit, University College London.

Parkhurst, G., 2000b. Link-and-ride - a longer-range strategy for car-bus interchange. Traffic

Engineering and Control, 41, 319-324.

Parkhurst, G., and Stokes, G., 1994. Park and Ride in Oxford and York: Report of Surveys. Oxford: University of Oxford Transport Studies Unit.

Pickett, M.W., and Gray, S.M., 1996. The Effectiveness of Bus-Based Park and Ride. Project Report 207. Crowthorne, Berkshire. Transport Research Laboratory.

SYPTE - South Yorkshire Passenger Transport Executive, 1995. Unpublished Data.

TAS Partnership, 2007. Park \& Ride Great Britain: a survey and report. 4th ed. London: TAS Partnership.

White, C.J., 1977. Park and Ride in Oxford and a Survey to Investigate the Possibility of Closing the Botley Road Site. Unpublished Student Project. Department of Geography, University of Reading.

WSA - W.S. Atkins, 1998. The Travel Effects of Park and Ride. Epsom: W.S. Atkins Planning Consultants (for DETR). 